\title{
中国被子植物濒危等级的评估
}

\begin{tabular}{|c|c|c|c|c|c|}
\hline 覃海宁 ${ }^{*}$ & 赵莉娜 1,2 & 于胜祥 ${ }^{1}$ & 刘慧圆 1,3 刘 & 夏念和 ${ }^{5}$ & 彭 \\
\hline $4=$ & 张志翔 ${ }^{7}$ & 何兴金 ${ }^{8}$ & 尹林克 ${ }^{9} \quad$ 林余霖 ${ }^{10}$ & 刘全儒 3 & 侯元同 ${ }^{11}$ \\
\hline 演 $^{12}$ & 刘启 新 ${ }^{13}$ & 曹 伟 14 & 李建强 ${ }^{15}$ & 金效华 1 & 高天刚 ${ }^{1}$ \\
\hline & 马海 & 耿玉英 ${ }^{18}$ & 金孝锋 19 & 宏 21 & 蔡 \\
\hline & 勇 24 & $飞^{2,2}$ & 赖阳均 ${ }^{26}$ 刘 & 林秦文 ${ }^{25}$ & 薛纳新 ${ }^{1}$ \\
\hline
\end{tabular}

1 (中国科学院植物研究所系统与进化植物学国家重点实验室, 北京 100093) 2 (中国科学院大学生命科学学院, 北京 100049) 3 (北京师范大学生命科学学院, 北京 100875) 4 (中央民族大学生命科学学院, 北京 100081)

5 (中国科学院华南植物园, 广州 510650) 6 (中国科学院昆明植物研究所东亚植物多样性与生物地理学重点实验室, 昆明 650201) 7 (北京林业大学自然保护区学院, 北京 100083) 8 (四川大学生命科学学院, 成都 610064)

9 (中国科学院新疆生态与地理研究所, 乌鲁木齐 830011) 10 (中国医学科学院北京协和医学院药用植物研究所, 北京 100193)

11 (曲阜师范大学生命科学学院, 山东曲阜 273165) 12 (广西壮族自治区中国科学院广西植物研究所, 广西桂林 541006)

13 (江苏省中国科学院植物研究所, 南京 210014) 14 (中国科学院沈阳应用生态研究所, 沈阳 110016)

15 (中国科学院武汉植物园, 武汉 430074) 16 (中国科学院西北高原生物研究所, 西宁 810008)

17 (云南大学生命科学学院, 昆明 650091) 18 (中国科学院植物研究所植被与环境变化国家重点实验室, 北京 100093)

19 (杭州师范大学生命与环境科学学院, 杭州 310036) 20 (西北农林科技大学生命科学学院, 陕西杨凌 712100)

21 (云南省林业科学院, 昆明 650204) 22 (环境保护部自然生态保护司, 北京 100035)

23 (中国环境科学研究院, 北京 100012) 24 (环境保护部南京环境科学研究所, 南京 210042)

25 (中国科学院植物研究所北京植物园, 北京 100093) 26 (中国科学院南京地质古生物研究所, 南京 210008)

摘要: 本文基于文献和标本信息收集以及专家提供的数据, 运用IUCN濒危物种红色名录方法首次对中国范围内 所有已知被子植物进行灭绝风险评估。结果显示, 在评估的 30,068 种被子植物中, 灭绝等级(含灭绝、野外灭绝、 地区灭绝)共计 40 种; 受威胁等级(极危、濒危、易危) 3,363种, 受威胁比例为 $11.18 \%$ 。从空间分布看, 我国受威胁 被子植物主要集中分布在西南地区以及台湾、海南等岛屿, 且主要分布在中低海拔地区。对受威胁物种的分析结 果表明, 包括原生植被破坏在内的生境丧失及破碎化是我国被子植物濒危的首要因子, 涉及约 $84.1 \%$ 的受威胁物 种; 过度采挖和物种内在系统问题位列致危因子的第二、三位, 分别涉及 $38 \%$ 和 $14 \%$ 的物种。其他的致危因子包括 外来入侵种在内的种间竞争、环境污染、自然灾害和全球气候变化等。一个物种的致危因子往往是多方面的。本次 评估与2004年红色名录相比, 生境变化、实施保护措施及分类学新修订使一些物种的濒危等级发生了变化, 这也印 证了红色名录是一个动态的系统, 需要根据最新信息进行更新, 以便为生物多样性保护提供实时准确的基础数据。

关键词: IUCN 红色名录; 灭绝风险评估; 威胁因子; 被子植物; 保护

\section{Evaluating the endangerment status of China's angiosperms through the red list assessment}

Haining Qin ${ }^{1 *}$, Lina Zhao ${ }^{1,2}$, Shengxiang $\mathrm{Yu}^{1}$, Huiyuan $\mathrm{Liu}^{1,3}$, Bo Liu ${ }^{4}$, Nianhe Xia ${ }^{5}$, Hua Peng ${ }^{6}$, Zhenyu $\mathrm{Li}^{1}$, Zhixiang Zhang, Xingjin $\mathrm{He}^{8}$, Linke Yin ${ }^{9}$, Yulin $\mathrm{Lin}^{10}$, Quanru Liu', Yuantong Hou ${ }^{1}$, Yan Liu ${ }^{12}$, Qixin Liu ${ }^{13}$, Wei Cao ${ }^{14}$, Jianqiang $\mathrm{Li}^{15}$, Shilong Chen ${ }^{16}$, Xiaohua $\mathrm{Jin}^{1}$, Tiangang $\mathrm{Gao}^{1}$, Wenli Chen ${ }^{1}$, Haiying $\mathrm{Ma}^{17}$, Yuying Geng $^{18}$, Xiaofeng Jin ${ }^{19}$, Chaoyang Chang ${ }^{20}$, Hong Jiang ${ }^{21}$, Lei Cai ${ }^{22}$, Chunxin Zang ${ }^{23}$, Jianyong $\mathrm{Wu}^{24}$, Jianfei $\mathrm{Ye}^{2,25}$, Yangjun Lai ${ }^{26}$, Bing Liu', Qinwen $\mathrm{Lin}^{25}$, Naxin Xue ${ }^{1}$

1 State Key Laboratory of Systematic and Evolutionary Botany, Institute of Botany, Chinese Academy of Sciences, Beijing 100093

收稿日期: 2017-05-27; 接受日期: 2017-07-11

基金项目: 环境保护部生物多样性保护专项一一中国高等植物红色名录和国家标本资源共享平台一一植物子平台(2005DKA21401)

* 通讯作者 Author for correspondence. E-mail: hainingqin@ibcas.ac.cn 
2 College of Life Sciences, University of Chinese Academy of Sciences, Beijing 100049

3 School of Life Sciences, Beijing Normal University, Beijing 100875

4 College of Life and Environmental Sciences, Minzu University of China, Beijing 100081

5 South China Botanical Garden, Chinese Academy of Sciences, Guangzhou 510650

6 Key Laboratory for Plant Diversity and Biogeography of East Asia, Kunming Institute of Botany, Chinese Academy of Sciences, Kunming 650201

7 School of Nature Conservation, Beijing Forestry University, Beijing 100083

8 College of Life Sciences, Sichuan University, Chengdu 610064

9 Xinjiang Institute of Ecology and Geography, Chinese Academy of Sciences, Urumqi 830011

10 Institute of Medicinal Plant Development, Chinese Academy of Medicinal Science \& Peking Union Medicinal College, Beijing 100193

11 College of Life Sciences, Qufu Normal University, Qufu, Shandong 273165

12 Guangxi Institute of Botany, Guangxi Zhuang Autonomous Region and the Chinese Academy of Sciences, Guilin, Guangxi 541006

13 Institute of Botany, Jiangsu Province and Chinese Academy of Sciences, Nanjing 210014

14 Institute of Applied Ecology, Chinese Academy of Sciences, Shenyang 110016

15 Wuhan Botanical Garden, Chinese Academy of Sciences, Wuhan 430074

16 Northwest Institute of Plateau Biology, Chinese Academy of Sciences, Xining 810008

17 School of Life Sciences, Yunnan University, Kunming 650091

18 State Key Laboratory of Vegetation and Environmental Change, Institute of Botany, Chinese Academy of Sciences, Beijing 100093

19 College of Life and Environmental Sciences, Hangzhou Normal University, Hangzhou 310036

20 College of Life Sciences, Northwest Agriculture \& Forestry University, Yangling, Shanxi 712100

21 Yunnan Academy of Forestry, Kunming 650204

22 Ministry of Environment Protection of the People's Republic of China, Beijing 100035

23 Chinese Research Academy of Environmental Sciences, Beijing 100012

24 Nanjing Institute of Environmental Sciences, Ministry of Environmental Protection, Nanjing 210042

25 Beijing Botanical Garden, Institute of Botany, Chinese Academy of Sciences, Beijing 100093

26 Nanjing Institute of Geology and Palaeontology, Chinese Academy of Sciences, Nanjing 210008

Abstract: All known species of Angiosperms in China were evaluated according to the IUCN Red List Categories and Criteria: Version 3.1, Second edition and the Guidelines for Application of IUCN Red List Criteria at Regional and National Levels, Version 4.0. Of the 30,068 species evaluated, 21 species were found Extinct (EX), 9 species were Extinct in the Wild (EW), 10 species were Regionally Extinct (RE), 518 species were Critically Endangered (CR), 1,152 species were Endangered (EN), 1,693 species were Vulnerable (VU), 2,538 species were Near Threatened (NT), 21,132 species were Least Concern (LC), and 2,995 species were Data Deficient (DD). The results show that 3,363 species, representing $11.2 \%$ of the evaluated species, were identified as threatened (CR, EN and VU). The main portion of threatened species occurs below 2,000 $\mathrm{m}$ elevation in southwestern and southern China. Habitat loss and degradation, over-collecting by humans, and intrinsic factors are the three leading threats to angiosperms in China. Comparisons of the status of taxa on this Red List to those evaluated by Wang \& Xie (2004) show changes in the names and categories of some taxa due to land use pressures, the impact of conservation measures to improve the status of some species as well as new information, such as from taxonomic revisions. Therefore, there is a need for future data collection and reevaluation of the red list.

Key words: IUCN Red List; risk assessment of extinction; threats; angiosperms; conservation

被子植物是植物界中最晚发生, 又最具生命力 的植物类群, 它占据着现代地球陆地表面的大部分 空间, 是世界植被的主要组成成分, 与人类社会发 展及经济生活密切相关。全世界约有被子植物 360,000多种(Royal Botanic Gardens Kew, 2016), 中 国有28,000-30,000种, 约占全球的 8\% (Wu et al,
2013; 王利松等, 2015)。

被子植物也是我国濒危植物的主体，许多种类 已经被列入国内保护植物名录和国际公约保护物 种名录。例如, 1999年发布的《国家重点保护野生 植物名录(第一批)》包括419种13类(指种以上分类 等级), 其中被子植物就占了 361 种 5 类, 占总种数的 
85\%以上(国家林业局和国家农业部，1999); 在 CITES附录物种清单中, 我国共有约 1,600 种植物被 列入, 其中绝大部分是被子植物的兰科植物(中华 人民共和国濒危物种进出口管理办公室和中华人 民共和国濒危物种科学委员会, 2013)。

当今人类社会生存和可持续发展面临着人口、 环境、自然资源、能源和粮食等五大难题。生物多 样性丧失是环境遭受破坏的主要后果之一, 保护 生物多样性刻不容缓。然而, 对全部物种实施保护 是不可行的。“以最少的资源保护尽可能多的物种, 以最优的资源保护最需要保护的物种” 就成为生物 多样性保护工作的一项重要原则(Mittermeier et al, 1998; Myers et al, 2000; Novacek \& Cleland, 2001)。 评估物种的濒危等级是制订物种保护优先顺序的 重要依据。据Miller等(2007)调查, 世界上许多国家 都发布了濒危物种名录, 而且主要是采用世界自 然保护联盟(International Union for Conservation of Nature, IUCN)的物种红色名录(简称IUCN红色名 录)作为标准进行评估。IUCN红色名录系统是公认 的最为全面、客观、合理的等级系统。首先是因为 该系统定义明确; 其次, 其标准指标客观合理且 不兄余; 第三, 其濒危等级(risk categories)能够在 多个尺度范围内和不同生物类群中使用; 最后, 该系统允许采用一些不确定性信息评估物种的灭 绝风险(de Grammont \& Cuarón, 2006; Rohan et al, 2009; IUCN Standards and Petitions Subcommittee, 2011)。

早在1991年, 我国就开始了中国植物红皮书 的编写(傅立国和金鉴明, 1991)。《中国物种红色名 录第一卷: 红色名录》(汪松和解炎, 2004)第一次采 用IUCN红色名录标准(3.1版)对中国植物进行评估, 共评估了 4,408种种子植物, 包括全部裸子植物 (226种)和部分被子植物(4,182种)。其中, 3,624种被 子植物被评为受威胁等级 (CR, EN和VU), 占被子 植物总评估数的 $86.7 \%$ 。该书的出版为了解中国被 子植物濒危状况及制订保护对策和行动实施提供 了重要信息。此次中国高等植物红色名录评估, 涉 及中国境内全部已知被子植物 3 万余种, 其中约一 半物种为中国特有, 因而具有全球性的意义。此 外, 全面评估中国植物区系的濒危状况对我国政 府制订生物多样性保护战略和国际履约具有重要 的意义。

\section{1 评估基准}

评估主要依据IUCN全球物种濒危等级的评估 标准(IUCN, 2012a)。然而, 全球标准应用于国家或 地区层面时会有一些问题。例如, 在全球被定为无 危(Least Concern, LC)的分类群, 可能在某个特定 区域内的数量很少或正在衰退, 或仅仅因为它们处 于全球分布区的边缘而被划为极危(Critically Endangered, CR)。反之, 根据数量和分布区存在全球 性衰退的资料被划分到易危(VU)的分类群, 可能因 其在特定地区种群数稳定而被定为无危等。为了解 决这个问题, 本次分级评估还参考了 IUCN红色名 录地区及国家层面指南(IUCN, 2012b)。《中国高等 植物红色名录》共采用 IUCN 红色名录的灭绝 (Extinct, EX)、野外灭绝(Extinct in Wild, EW)、地区 灭绝(Regionally Extinct, RE)、极危(Critically Endangered, CR)、濒危 (Endangered, EN)、易危 (Vulnerable, VU)、近危(Near Threatened, NT)、无危 (Least Concern, LC)和数据缺乏(Data Deficient, DD) 等 9 个等级。其中, 确定 $\mathrm{VU} 、 \mathrm{EN} 、 \mathrm{CR}$ 三个受威胁等 级所依据的 5 个标准, 包括以居群动态信息为主的 $\mathrm{A}$ 标准、分布范围为主的B标准、小种群为主的C标 准、极小种群为主的 $\mathrm{D}$ 标准以及根据灭绝速率评估 的E标准均有一定的量化指标(或称阈值) (IUCN Standards and Petitions Subcommittee, 2011; IUCN, 2012a)。各个等级定义、分级架构及受威胁等级评 估标准量化指标详见附录1。

\section{2 评估流程和具体做法}

IUCN红色名录评估主要是利用种群数量、分 布范围及下降(减少)比例等信息对目标物种进行野 外灭绝风险评估。此次评估依照IUCN评估流程, 由 数据收集、评估、审核、补充完善和撰写评估报告 等4个阶段组成(IUCN, 2012c)。并在此框架内, 制订 了符合中国植物区系本底及研究基础具体情况的 实施细则和补充方案。例如在数据收集阶段, 首先 制订一份实时更新和权威的基础名录, 然后采取线 上与线下、公开与手稿兼顾的方式进行数据收集。 此外, 我们还广泛邀请全国专科专属专家提供物种 评估数据, 以弥补种群野外数据的不足。在正式评 估之前, 我们按照一定的遴选标准, 将中国植物划 分为重点(评估)物种与非重点(评估)物种进行差异 
化处理，并通过培训及国际交流，建立起一支专业 化评估队伍, 确保整个项目评估严格规范地按照 IUCN标准进行。

\section{1 确定评估对象与收集评估数据}

《中国植物志》和Flora of China是中国植物的 “户口簿”, 它们为我们提供了中国植物多样性的重 要基础数据。但志书编写出版周期较长, 不能及时 反映分类学 (名称)处理的最新进展, 加之不同作者 采用的系统时有冲突, 因而仍然需要一个信息及时 更新和权威的植物名录作为红色名录评估的基础。

我们以《中国生物物种名录》(Catalogue of Life China, 简称“CoL-China”)的高等植物部分(Qin et al, 2013)作为红色名录基础名录。该名录经由多位分类 学家参考Flora of China、《中国植物志》以及新近 发表文献修订而成, 是目前数据较新和广为接受的 中国高等植物名录。此外, 我们还依据最新资料和 专家意见对CoL-China的数据作进一步处理, 包括 对一些属种进行必要的修订, 以及按照IUCN红色 名录规则剔除非中国原产的外来栽培植物、杂交种 和变种及亚种以下等不宜评估类群(即“不宜评估”, Not Applicable, NA)。最终形成的红色名录被子植物 基础库包括 250 科 2,756 属30,068种, 其中特有种 16,676种, 特有率55.46\%。

评估所需物种数据的数量和质量是评估成功 与否和评估结果是否被认可的关键。对于评估中国 这样一个大型植物区系来说, 数据收集是最大的挑 战。一方面, 中国植物物种丰富, 基数大; 另一方面, 除少数备受关注的珍稀濒危保护物种外, 大多数中 国植物缺乏种群大小、个体数量和分布面积及变动 趋势等评估所需信息。我们广泛邀请全国植物分类 专业人才, 结合项目组所搜集到的数据, 保证了在 短时间内获得大量具有相当可信度的植物数量及 分布资料。一方面, 项目组通过实体图书馆及网络 平台, 收集中国高等植物物种相关文献及标本资料, 包括分类、区系与分布、资源利用及保护(栽培、繁 育)等主题内容。其中, “中国知网”和 “维普” 是最常 使用的搜索平台, 而标本信息则来自中国数字植物 标本馆 $(\mathrm{CVH})$ (http://www.cvh.ac.cn)数百万份数字 标本。二是邀请专家提供信息。共有 280 多位植物 学专家参与被子植物评估工作, 他们就专长的科属 类群, 或提供数据, 或审核红色名录评估结果。专 家提交的数据包括物种名称(变化)、地理分布及野
外居群状况、威胁因子、利用方式和保护现状等, 包 括一些专家本人没有正式发表的观察实验数据, 十 分宝贵。

\section{2 “预评估”(pre-assessment)与评估}

IUCN 物种生存委员会(Species Survival Commission, SSC)建议应该对所有的植物分类群的濒危 状态进行评估，不管它们是否可能面临灭绝的危险 (Hilton-Taylor, 2000)。但对中国、南非、巴西等生 物多样性大国评估时所遇到的巨大困难，例如，同 时分级处理数万种植物所需技术框架及大量人力 资源等并没有提供具体的解决方案。我们借鉴南非 (全球首个也是唯一一个实现对全部国产植物进行 评估的生物多样性大国)的成功经验, 即首先甄别 出那些可能濒危和引起保护关注(conservation concern)的类群, 作为进一步开展调查及评估的优先类 群, 从而达到既能实现全面评估, 又可避免不必要 的人力资源浪费的目的 (Raimondo et al, 2009, 2013)。

我们的策略和具体做法是将以往珍稀濒危保 护名录及其他重要物种列入需要优先调查及评估 物种(称“重点物种”, 下同), 包括: (1)《中国物种红 色名录》(汪松和解炎, 2004)、《国家重点保护野生 植物名录(第一批)》(国家林业局和国家农业部, 1999) 以及各类国家级和省级珍稀濒危保护植物名 录上的物种; (2)具有重要经济、科学和文化价值, 以 及生态意义和遗传价值的珍稀濒危物种; (3)分布狭 窄、数量稀少的物种, 包括中国特有属和寡种属的 种类。反之, 上述三类名单之外的其他物种则归入 “非重点物种”名单, 包括那些广泛分布、数量较多 和常见的种类, 以及数量稀少但分布在人迹罕至或 高海拔地区，不易受到威胁的物种。

经过上述规则划分生成的两类名录初稿, 再由 项目组核对志书资料和标本信息，并分请专家审核， 最终把我国被子植物 30,000余种划分为“重点物 种”12,000多种和“非重点物种”(图1) 17,000多种。简 言之, 经过遴选划分出的“重点物种”, 代表了基于 现有资料判读其濒危程度可能比较严重或亟须保 护关注的种类, 需要进一步调查和进行灭绝风险评 估, 而“非重点物种”则为野外居群安全和濒危可能 性很小，包括常见和广泛分布的种类。在随后的“评 估”阶段中, “非重点物种”即可按照IUCN红色名录 濒危等级定义直接被评估为无危(LC)。 


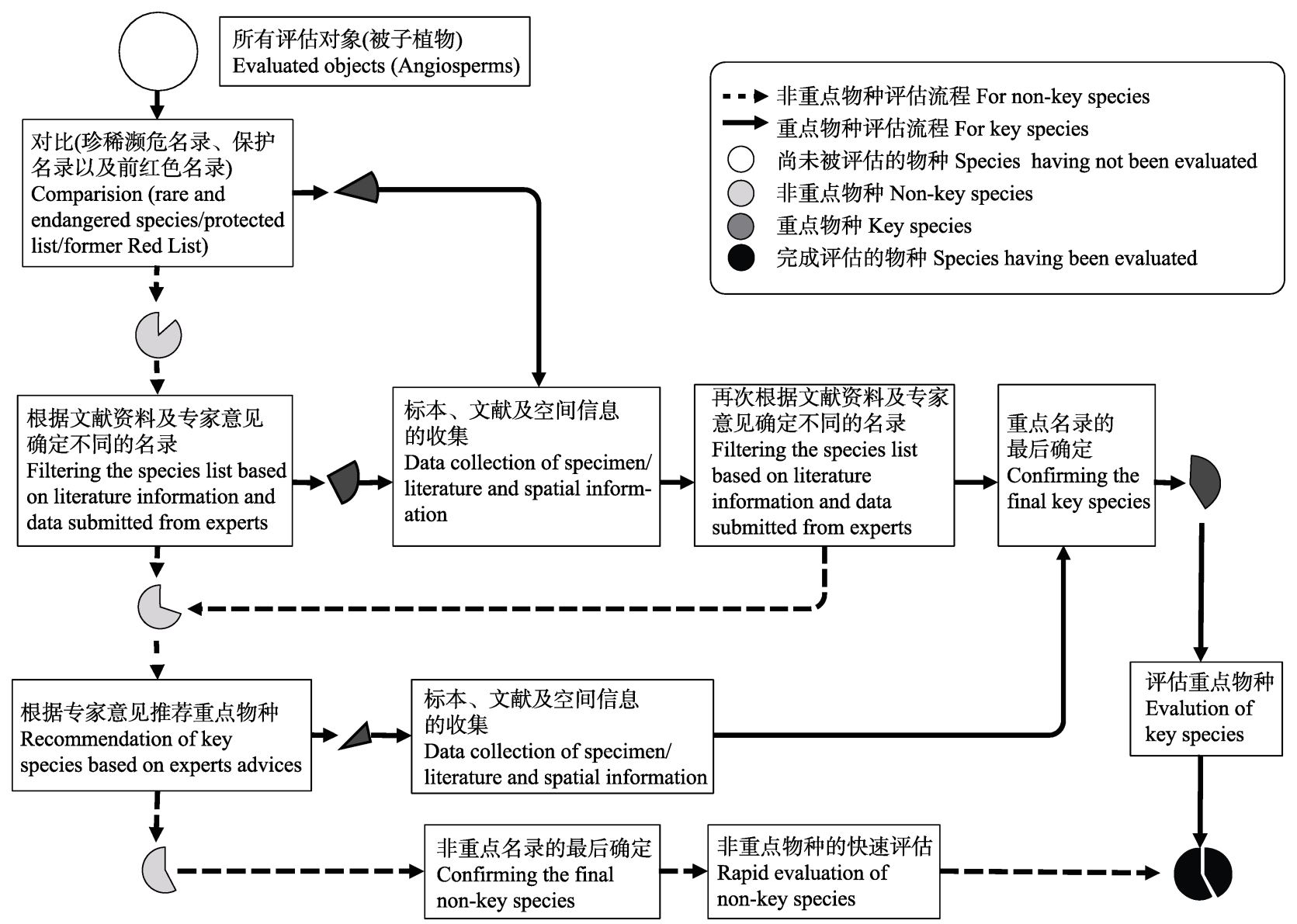

图1 区分“重点”与“非重点”物种流程图

Fig. 1 The roadmap undertaken to differentiate key and non-key species (adopted from Raimondo et al, 2009)

上述两类植物的划分法突出了保护关注类群 和重点调查类群, 既保证了后续评估能按照IUCN 红色名录的方法和原理进行, 又节省了时间, 提高 了工作效率, 是评估一个超大植物区系的有效手段。

“重点”与“非重点”名单的区分是我们在预评估 (pre-assessment)阶段加入的“自选动作”。该阶段是 IUCN为正式评估前设立的“热身”阶段, 要求对收 集到的各种来源数据进行归纳整理, 成为适合于红 色名录评估的数据形式及类型, 目的是让评估者了 解和掌握现有数据的状况及大致的评估效果, 为正 式评估作好铺垫(IUCN, 2012c)。

“评估”阶段主要是由项目组成员依据整理好的 物种信息资料, 以IUCN红色名录等级及指标(全球 标准及地区标准)为标准, 对物种一一进行评估。首 先是依据全球性标准(IUCN, 2012a)对目标物种进 行评估, 得出初步等级。若属于受威胁级(CR, EN, $\mathrm{VU})$ 之物种, 再依照量化指标评定其等级, 每个物
种都应用A-E所有的标准进行评估，符合任何一条 标准即予以列入; 如果符合多条标准或亚标准, 则 每一条都要列出; 如果评估信息能够得到多个等级, 则以濒危程度最高的等级作为最终的等级。

\section{3 审查及复审}

按照IUCN红色名录评估规则及要求, 每一个 物种的评估结果都需要经由独立的第三方进行审 查(review), 以确定濒危等级和标准是否运用正确 以及是否有足够的数据支持。本次评估的每个物种 均由未参加评估的项目组其他成员或邀请一至数 名类群专家进行审查。专家审查形式包括会议审查 和通讯审查。在被子植物评估(结果)审查过程中, 共 有87位专家接受了评估小组成员组织的一对一审 核。20余位专家通过通讯方式完成了红色名录的审 查工作。每位专家在接受简短的评估方法培训后, 方可对所专长的类群进行审查, 重点审查被评为受 威胁等级 $(\mathrm{CR}, \mathrm{EN}$ 和 VU) 的物种以及各科属中可能 
遗漏的重要物种。最后, 评估结果交由19位权威专 家组成的中国高等植物红色名录指导委员会复审, 以确保整个评估的准确性及专业性。

\section{4 补充完善和形成评估报告}

依据专家审核意见和项目组内部自查结果, 评 估小组进一步补充、完善评估信息、修正濒危等级 及支持指标, 以保证评估结果的一致性。极个别评 估结果还存在较大争议时再行专家审查。

完成全部评估后, 我们依据IUCN格式要求撰 写红色名录评估报告, 包括评估的背景、评估方法、 结果及其分析, 重点是分析物种致危因子; 对于受 威胁等级物种, 则撰写一种一份的评估说明, 内容 包括物种识别特征、分布与生境、居群大小与减少 趋势等评估依据以及参考文献等信息。

\section{3 结果和分析}

本次评估被子植物 30,068 种, 占中国高等植物 红色名录评估物种总数的 $84 \%(30,068 / 35,784)$ 。评 估结果表明, 被子植物中有21种为灭绝(EX), 9种野 外灭绝(EW), 10种地区性灭绝(RE), 518种极危(CR), 1,152种濒危(EN), 1,693种易危(VU), 2,538种近危 (NT), 21,132种无危(LC), 2,995种数据缺乏(DD) (表 1)。合计灭绝物种 40 种(表2); 受威胁物种(CR、EN、 VU) 3,363种, 占评估物种的 $11.18 \%(3,363 / 30,068)$ 。 需要指出的是, 在本评估中, 凡台湾和香港地区特 有种, 其等级直接采用当地红色名录评估工作的结 果(Hu et al, 2003; Wang et al, 2012)。

此次评估的被子植物中, 1-3个县狭域分布的

表1 中国被子植物红色名录各濒危等级的物种数及其占被 子植物总种数的比例

Table 1 Species number of each endangerment categories and their proportion to China's angiosperms species

\begin{tabular}{ll} 
等级 & $\begin{array}{l}\text { 物种数(\%) } \\
\text { No. of species (\%) }\end{array}$ \\
\hline Categories & $21(0.07)$ \\
灭绝 Extinct (EX) & $9(0.03)$ \\
野外灭绝 Extinct in wild (EW) & $10(0.03)$ \\
地区灭绝 Regional Extinct (RE) & $518(1.72)$ \\
极危等级 Critically Endangered (CR) \\
濒危 Endangered (EN) & $1,152(3.83)$ \\
易危 Vulnerable (VU) & $1,693(5.63)$ \\
近危 Near Threatened (NT) & $2,538(8.43)$ \\
无危 Least Concern (LC) & $21,132(70.28)$ \\
数据缺乏 Data Deficient (DD) & $2,995(9.96)$ \\
总计 Total & $30,068(100)$ \\
\hline
\end{tabular}

表2 中国被子植物灭绝种(灭绝、野外灭绝、地区性灭绝) Table 2 The angiosperms species listed as Extinct, Extinct in the Wild, and Regionally Extinct in China

\begin{tabular}{|c|c|}
\hline $\begin{array}{l}\text { 科名 } \\
\text { Family }\end{array}$ & $\begin{array}{l}\text { 种名 } \\
\text { Species }\end{array}$ \\
\hline \multicolumn{2}{|l|}{ 灭绝 EX (Extinct) } \\
\hline 番荔枝科 Annonaceae & 尖花藤 Friesodielsia hainanensis \\
\hline 菊科 Asteraceae & 小叶䝴吾 Ligularia parvifolia \\
\hline 秋海棠科 Begoniaceae & 保亭秋海棠 Begonia sublongipes \\
\hline 桦木科 Betulaceae & 盐华 Betula halophila \\
\hline 白玉䙃科 Corsiaceae & 白玉䉓 Corsiopsis chinensis \\
\hline 胡颓子科 Elaeagnaceae & 柳州胡颓子 Elaeagnus liuzhouensis \\
\hline 杜鹃花科 Ericaceae & $\begin{array}{l}\text { 小溪洞杜鹃 } \\
\text { Rhododendron xiaoxidongense }\end{array}$ \\
\hline 苦苍苔科 Gesneriaceae & 圆果苣苔 Gyrogyne subaequifolia \\
\hline 唇形科 Lamiaceae & 干生铃子香 Chelonopsis siccanea \\
\hline 唇形科 Lamiaceae & 喜雨草 Ombrocharis dulcis \\
\hline 木通科 Lardizabalaceae & $\begin{array}{l}\text { 倒心叶野木瓜 } \\
\text { Stauntonia obcordatilimba }\end{array}$ \\
\hline 樟科 Lauraceae & 宁明琼楠 Beilschmiedia ningmingensis \\
\hline 樟科 Lauraceae & 华菳润楠 Machilus salicoides \\
\hline 百合科 Liliaceae & 单花百合 Lilium stewartianum \\
\hline 兰科 Orchidaceae & 单花美冠兰 Eulophia monantha \\
\hline 兰科 Orchidaceae & 南川盆距兰 \\
\hline & Gastrochilus nanchuanensis \\
\hline 兰科 Orchidaceae & 明潭羊耳赫 Liparis hensoaensis \\
\hline 兰科 Orchidaceae & 峨眉带唇兰 Tainia emeiensis \\
\hline 无患子科 Sapindaceae & 爪耳木 Lepisanthes unilocularis \\
\hline 玄参科 Scrophulariaceae & 矮马先蒿 Pedicularis humilis \\
\hline 马鞭草科 Verbenaceae & $\begin{array}{l}\text { 小叶澜沧豆腐柴 } \\
\text { Premna mekongensis var. meiophylla }\end{array}$ \\
\hline \multicolumn{2}{|c|}{ 野外灭绝 EW (Extinct in the Wild) } \\
\hline 五加科 Araliaceae & 三七 Panax notoginseng \\
\hline 杜鹃花科 Ericaceae & 枯鲁杜鹃 Rhododendron adenosum \\
\hline 杜鹃花科 Ericaceae & 乌来杜鹃 Rhododendron kanehirae \\
\hline 苦苣苔科 Gesneriaceae & 焰苍唇柱苍苔 Chirita spadiciformis \\
\hline 水鳖科 Hydrocharitaceae & 拟纤细茨藻 Najas pseudogracillima \\
\hline 百合科 Liliaceae & $\begin{array}{l}\text { 华南蜘蛛抱蛋 } \\
\text { Aspidistra austrosinensis }\end{array}$ \\
\hline 睡菜科 Menyanthaceae & 龙潭苦菜 Nymphoides lungtanensis \\
\hline $\begin{array}{l}\text { 鼠李科 Rhamnaceae } \\
\text { 姜科 Zingiberaceae }\end{array}$ & $\begin{array}{l}\text { 鄂西鼠李 Rhamnus tzekweiensis } \\
\text { 细莪术 Curcuma exigua }\end{array}$ \\
\hline \multicolumn{2}{|c|}{ 地区灭绝 RE (Regionally Extinct) } \\
\hline 凤仙花科 Balsaminaceae & 水角 Hydrocera triflora \\
\hline 薯莪科 Dioscoreaceae & 吊罗薯蓣 Dioscorea poilanei \\
\hline 壳斗科 Fagaceae & 闭壳柯 Lithocarpus cryptocarpus \\
\hline 小二仙草科 Haloragaceae & 四荵狐尾藻 Myriophyllum tetrandrum \\
\hline 水鳖科 Hydrocharitaceae & 水菜花 Ottelia cordata \\
\hline 木兰科 Magnoliaceae & 线毛含笑 Michelia velutina \\
\hline 兰科 Orchidaceae & 蒙自石豆兰 Bulbophyllum yunnanense \\
\hline $\begin{array}{l}\text { 眼子菜科 Potamogetona- } \\
\text { ceae }\end{array}$ & 高山眼子菜 Potamogeton alpinus \\
\hline 山榄科 Sapotaceae & 云南藏榄 Diploknema yunnanensis \\
\hline 马鞭草科 Verbenaceae & 塔序豆腐柴 Premna pyramidata \\
\hline
\end{tabular}


有 10,140 种，占被子植物评估总数 $33.72 \%$ 。受威胁 物种中, 特有种 2,267 种, 占 $67.41 \%(2,267 / 3,363)$, 狭域分布种1,997种, 占59.38\%。特有种中, 受威胁 比例为 $13.6 \%(2,267 / 16,676)$, 非特有种濒危比例 $8.18 \%(1,096 / 13,392)$ 。这说明特有种及狭域分布种 比非特有种及广布种具有更高的濒危程度, 面临更 高的灭绝风险。

\section{1 灭绝物种}

被子植物灭绝物种有 40 种(表2), 分属 28 科 37 属。其中特有种 29 种, 木本植物24种。灭绝种类最 多的科依次为兰科(5种)和杜鹃花科(3种); 具有 2 种 的有苦苣苔科、水鳖科、唇形科、樟科、百合科和 马鞭草科; 其余 20 科各含 1 种。

物种灭绝的主要原因是生境的丧失和退化。人 类经济活动改变了土地使用性质, 使野生植物分布 地转变为农林植物栽培、养殖和放牧、城镇建设及 路网管线建设用地，从而蚕食毁坏了植物的原生境， 造成物种居群数量减少直至消失。还有少数物种的 灭绝主要是由于人为过度采集所导致的, 如五加科 的三七(Panax notoginseng)和木兰科的线毛含笑 (Michelia velutina)。此外, 根据IUCN指南, 当某个 类群超过50年没有被发现, 即使其生境并未遭到破 坏, 也被定为灭绝(IUCN, 2011)。但在本次评估中这 样的类群被定为“数据缺乏”(DD)。笔者认为, 只有
当某个类群的绝大部分栖息地都消失了, 并且对残 存的栖息地多次专门调查都没有发现该物种, 才能 确定为灭绝。

\section{2 受威胁物种科的分布}

被子植物中, 不同科的受威胁程度差别很大。 一般说来, 具有较大经济、药用和观赏价值的科, 受威胁程度比较高, 反之则受威胁程度较低。

对含 20 种以上科的受威胁情况分析发现, 受威 胁种数最多的科为兰科(653种), 占被子植物受威胁 总数的 $19.42 \%(653 / 3,363)$, 占本科物种数的 $43.48 \%$ 。兰科植物面临的最主要问题是原生植被遭 到破坏导致生境破碎、退化甚至丧失。此外，长期 的资源过度利用以及物种自身遗传多样性较低等 也是导致兰科植物濒危的重要因子(张玉武等, 2009; 秦卫华等, 2012)。受威胁物种数位列第二的是杜鹃 花科, 142 种, 分别占被子植物受威胁物种总数和本 科物种总数的 $4.22 \%$ 和 14.03 ; 其他依次为豆科(分别 占3.74\%和 $8.61 \%$ )、百合科(分别占3.06\%和13.55\%)、 樟科(分别占2.94\%和21.29\%)等(表3)。

从受威胁物种占该科物种总数比率看, 则受威 胁程度最高的是木兰科, 受威胁物种76种, 受威胁 比例高达 $67.3 \%$ 。这是因为木兰科植物普遍具有较 高的观赏价值, 是优良的庭园绿化树种, 长期以来 遭受过度移栽和损害性采种(子)所致。例如特有种

表3 被子植物中受威胁物种数最多的前15科(左列)和受威胁物种比例最高的前15科(右列)

Table 3 The top 15 families with the most threatened species numbers (left column) and the top 15 families with the largest proportion of threatened species (right column)

\begin{tabular}{|c|c|c|c|c|c|}
\hline $\begin{array}{l}\text { 科 } \\
\text { Family }\end{array}$ & $\begin{array}{l}\text { 种数 } \\
\text { Species number }\end{array}$ & $\begin{array}{l}\text { 受威胁种数 } \\
\text { No. of threatened species }\end{array}$ & $\begin{array}{l}\text { 科 } \\
\text { Family }\end{array}$ & $\begin{array}{l}\text { 种数 } \\
\text { Species number }\end{array}$ & $\begin{array}{l}\text { 受威胁种比例(\%) } \\
\% \text { of threatened species }\end{array}$ \\
\hline 兰科 Orchidaceae & 1,502 & 653 & 木兰科 Magnoliaceae & 113 & 67.3 \\
\hline 杜鹃花科 Ericaceae & 1,012 & 142 & 猕猴桃科 Actinidiaceae & 76 & 63.2 \\
\hline 豆科 Fabaceae & 1,463 & 126 & 苟药科 Paeoniaceae & 20 & 60 \\
\hline 百合科 Liliaceae & 760 & 103 & 薯蓣科 Dioscoreaceae & 58 & 53.4 \\
\hline 樟科 Lauraceae & 465 & 99 & 金缕梅科 Hamamelidaceae & 77 & 49.4 \\
\hline 山茶科 Theaceae & 346 & 91 & 马淣铃科 Aristolochiaceae & 82 & 48.8 \\
\hline 毛莨科 Ranunculaceae & 1,081 & 87 & 兰科 Orchidaceae & 1,502 & 43.5 \\
\hline 木兰科 Magnoliaceae & 113 & 76 & 黄杨科 Buxaceae & 25 & 40 \\
\hline 壳斗科 Fagaceae & 305 & 75 & 梧桐科 Sterculiaceae & 77 & 39 \\
\hline 苦苣苔科 Gesneriaceae & 496 & 73 & 槭树科 Aceraceae & 130 & 36.2 \\
\hline 菩薇科 Rosaceae & 1,206 & 62 & 棕㭣科 Arecaceae & 61 & 36.1 \\
\hline 景天科 Crassulaceae & 255 & 57 & 茶茱英科 Icacinaceae & 23 & 34.8 \\
\hline 禾本科 Poaceae & 1,881 & 53 & 安息香科 Styracaceae & 65 & 33.8 \\
\hline 小檗科 Berberidaceae & 308 & 48 & 杜英科 Elaeocarpaceae & 56 & 30.4 \\
\hline 猕猴桃科 Actinidiaceae & 76 & 48 & 胡桃科 Juglandaceae & 24 & 29.2 \\
\hline
\end{tabular}


宝华玉兰(Yulania zenii)仅分布在江苏省句容宝华山, 种群数量少, 加上人工过度采伐, 数量急剧减少, 目前成熟个体数不足 50 株, 濒危状况很严重, 被评 为 $\mathrm{CR}$ 等级。生境退化及丧失也是导致木兰科植物濒 危的主要因子之一。例如, 同样具有较大观赏价值 的馨香木兰 (Lirianthe odoratissima)、光叶玉兰 (Yulania dawsoniana)和香子含笑(Michelia gioi)就是 由于原生植被破坏导致其居群数量急剧减少而被 评为受威胁等级的。受威胁程度位列第二的是猕猴 桃科(48种), 受威胁比例 $63.2 \%$ 。其他依次为莳药 科、薯蓣科、金缕梅科、马兒铃科、兰科、黄杨科、 梧桐科、槭树科、棕榈科、茶茱英科、安息香科、 杜英科、胡桃科(图2)。

\section{3 受威胁物种省区分布}

受威胁物种在地理空间的分布也不平衡: 总体 上濒危物种数量由北往南递增, 由东往西递增, 这 与我国物种多样性的分布格局总体相似(Zhao et al, 2016)。西南各省区所含受威胁种数较高, 云南、四 川、广西和西藏位居前四(表4)。狭域分布(1-3个县) 受威胁种的分布也呈现类似的特点(表5)。若按单位 面积平均濒危物种数计算, 则最高省份为海南, 其 次为云南。究其原因, 一方面, 海南和云南位于我 国仅有的热带地区，物种资源本就十分丰富; 另一 方面, 此次调查显示, 海南和云南两地近年来快速 升温的热带经济林(作物)种植、基础建设开发以及
森林生态旅游热导致次生森林遭受破坏, 加剧了植 物生存环境的破碎化, 成为物种致危的主要因子。

\section{4 受威胁物种习性及生境}

在被子植物受威胁种中, 草本种和木本种数量 大致相当, 分别为 1,634 种和 1,470 种 (乔木和灌木), 另有藤本植物259种(表6)。一般来说，一个正常成熟 的植物区系, 木本植物与草本植物种类之比为 $1: 3$ 左右，而我国受威胁植物中木本植物种类占 $43 \%$, 说明木本植物濒危程度远高于草本植物。草本植物 中, 多年生草本占 $89 \%$, 表明该类型植物在草本种 类中比例较大, 濒危程度也高。据王振哲等(2012) 对台湾水生、附生、寄生和腐生等特殊习性植物的 分析结果, 这些物种的濒危程度普遍高于草本、木 本等常见类型。以常见的附生植物兰科植物为例, 其生长不仅受限于所依附的植物, 其本身更常常被 采挖作药材或园林观赏之用, 濒危程度自然很高。 但我们的统计结果与王振哲等(2012)的结论并不一 致, 这可能说明我们对本底数据的收集及分析还不 到位, 今后应该加强这方面工作。

对被子植物受威胁种的生境类型分析表明，森 林中分布的种类最多, 占 $84.7 \%$, 主要包括针叶林、 落叶阔叶林、常绿阔叶林、雨林、季雨林、红树林、 竹林等类型; 其次是灌从，占 $27.0 \%$; 位列第三、第 四的分别是包括农田、造林和种植园在内的人工植 被和草原草甸, 分别为13.3\%和12.5\% (表7)。

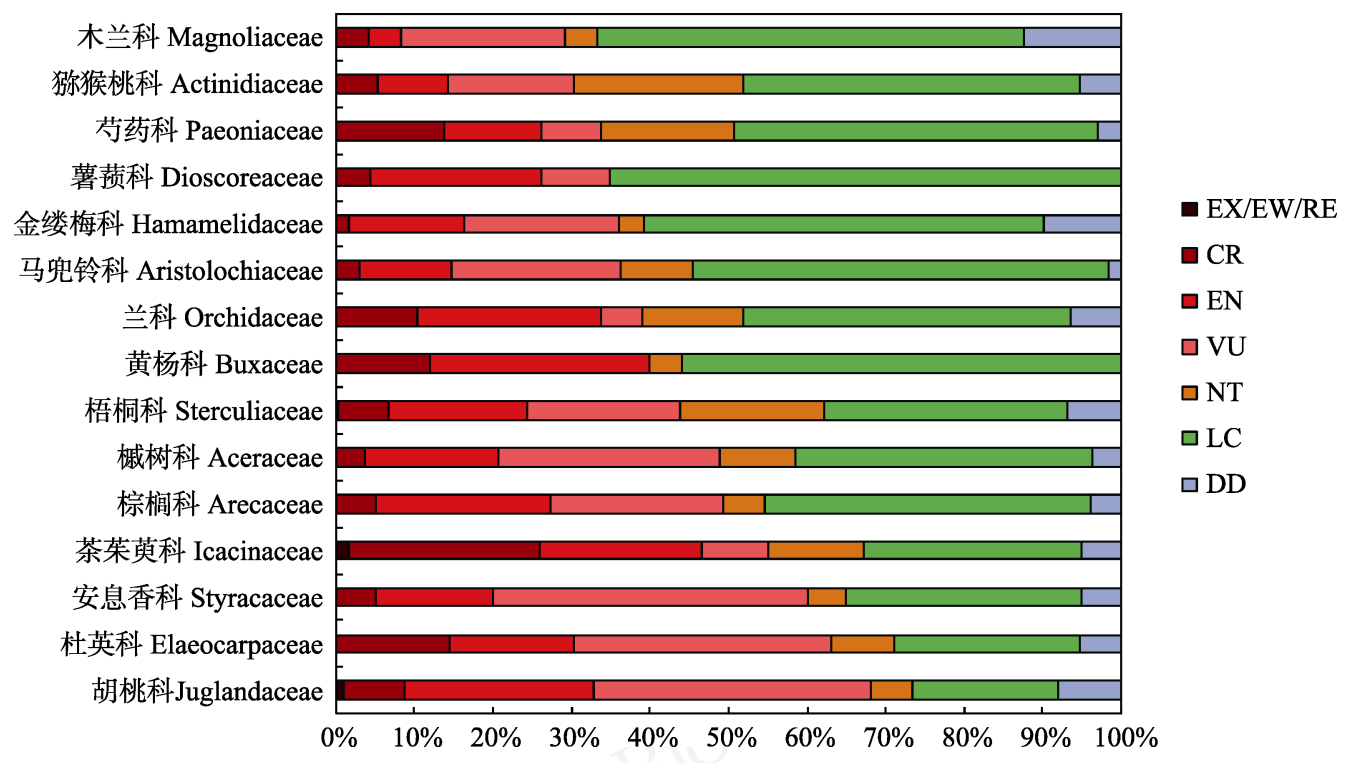

图2 被子植物中受威胁物种比例最高的前 15 科及各个濒危等级。濒危等级的代号同表1。

Fig. 2 The top 15 angiosperms families with the largest proportion of threatened species and their categories. The categories are the same as those in Table 1. 
表4 各省区被子植物受威胁物种统计。濒危等级同表1。

Table 4 Statistics of threatened angiosperms species at provincial level. The categories are the same as those in Table 1.

\begin{tabular}{|c|c|c|c|c|c|c|c|c|c|}
\hline & $\begin{array}{l}\text { 种数 } \\
\text { Species } \\
\text { number }\end{array}$ & $\begin{array}{l}\text { 受威胁种数 } \\
\text { No. of } \\
\text { threatened } \\
\text { species }\end{array}$ & $\begin{array}{l}\text { 受威胁比例 }^{2} \\
\% \text { of threat- } \\
\text { ened species }\end{array}$ & $\begin{array}{l}\text { 受威胁比例 }^{(8)} \\
\% \text { of threat- } \\
\text { ened species }\end{array}$ & & $\begin{array}{l}\text { 种数 } \\
\text { Species } \\
\text { number }\end{array}$ & $\begin{array}{l}\text { 受威胁种数 } \\
\text { No. of } \\
\text { threatened } \\
\text { species }\end{array}$ & $\begin{array}{l}\text { 受威胁比例 }^{(2)} \\
\% \text { of threat- } \\
\text { ened species }\end{array}$ & $\begin{array}{l}\text { 受威胁比例 }^{\circledR} \\
\% \text { of threat- } \\
\text { ened species }\end{array}$ \\
\hline 云南 Yunnan & 15,915 & 1,710 & 10.7 & 50.8 & 重庆 Chongqing & 1,062 & 73 & 6.9 & 2.2 \\
\hline 四川 Sichuan & 10,614 & 649 & 6.1 & 19.3 & 吉林 Jilin & 1,975 & 63 & 3.2 & 1.9 \\
\hline 广西 Guangxi & 7,082 & 646 & 9.1 & 19.2 & 江苏 Jiangsu & 1,651 & 58 & 3.5 & 1.7 \\
\hline 西藏 Tibet & 7,684 & 434 & 5.6 & 12.9 & 香港 Hong Kong & 844 & 57 & 6.8 & 1.7 \\
\hline 海南 Hainan & 3,609 & 394 & 10.9 & 11.7 & $\begin{array}{l}\text { 内蒙古 } \\
\text { Inner Mongolia }\end{array}$ & 2,208 & 57 & 2.6 & 1.7 \\
\hline 贵州 Guizhou & 5,828 & 381 & 6.5 & 11.3 & 河南 Henan & 1,997 & 56 & 2.8 & 1.7 \\
\hline 广东 Guangdong & 5,157 & 340 & 6.6 & 10.1 & 河北 Hebei & 1,997 & 49 & 2.5 & 1.5 \\
\hline 台湾 Taiwan & 4,529 & 302 & 6.7 & 9 & 辽宁 Liaoning & 1,791 & 47 & 2.6 & 1.4 \\
\hline 湖北 Hubei & 3,784 & 197 & 5.2 & 5.9 & $\begin{array}{l}\text { 黑龙江 } \\
\text { Heilongjiang }\end{array}$ & 1,872 & 47 & 2.5 & 1.4 \\
\hline 湖南 Hunan & 3,895 & 183 & 4.7 & 5.4 & 山西 Shanxi & 1,696 & 45 & 2.7 & 1.3 \\
\hline 浙江 Zhejiang & 3,301 & 158 & 4.8 & 4.7 & 青海 Qinghai & 2,190 & 45 & 2.1 & 1.3 \\
\hline 福建 Fujian & 3,477 & 157 & 4.5 & 4.7 & 山东 Shandong & 1,232 & 23 & 1.9 & 0.7 \\
\hline 陕西 Shaanxi & 3,640 & 141 & 3.9 & 4.2 & 宁夏 Ningxia & 879 & 17 & 1.9 & 0.5 \\
\hline 江西 Jiangxi & 3,194 & 129 & 4 & 3.8 & 北京 Beijing & 218 & 5 & 2.3 & 0.1 \\
\hline 甘肃 Gansu & 3,795 & 119 & 3.1 & 3.5 & 上海 Shanghai & 154 & 2 & 1.3 & 0.1 \\
\hline 新疆 Xinjiang & 3,325 & 116 & 3.5 & 3.4 & 澳门 Мacao & 92 & 0 & 0 & 0 \\
\hline 安徽 Anhui & 2,369 & 104 & 4.4 & 3.1 & 天津 Tianjin & 46 & 0 & 0 & 0 \\
\hline
\end{tabular}

(1) 各省被子植物种数基于红色名录基础名录统计(仅供参考) The numbers of angiosperms species in each province are drawn from the Red List database (for reference only)

(2) 各省受威胁种数与本省物种总数的比值 The ratio of threatened species number to total angiosperms species number of each province

(3) 各省受威胁种数与全国受威胁被子植物种总数的比值 The ratio of threatened species number to total number of threatened species of angiosperms in China

表5 各省独有的狭域分布(1-3县)受威胁被子植物种数(前 10省)

Table 5 The top 10 provinces with the most of threatened angiosperms species which are restrictedly distributed in 1-3 counties

\begin{tabular}{ll}
\hline & 种数 No. of species \\
\hline 云南 Yunnan & 644 \\
四川 Sichuan & 180 \\
广西 Guangxi & 174 \\
海南 Hainan & 103 \\
西藏 Tibet & 103 \\
新疆 Xinjiang & 59 \\
贵州 Guizhou & 54 \\
广东 Guangdong & 48 \\
重庆 Chongqing & 31 \\
浙江 Zhejiang & 24 \\
\hline
\end{tabular}

中国被子植物受威胁种(CR, EN, VU)主要分布 在中低海拔地区。我们将 $1,000 \mathrm{~m}$ 以下划分为低海拔, 1,000-2,000 $\mathrm{m}$ 为中海拔, 2,000-4,000 $\mathrm{m}$ 为高海拔, 4,000-5,500 m为极高海拔。统计显示, 受威胁植物
表6 被子植物受威胁种习性统计

Table 6 Habits of China's threatened angiosperms species

\begin{tabular}{lll}
\hline & 习性 Habit & 物种数 No. of species \\
\hline 草本 Herb & 一年生 Annual & 57 \\
& 两年生 Biennial & 15 \\
& 多年生 Perennial & 1,460 \\
& 其他 Others & 102 \\
& 小计 Subtotal & 1,634 \\
灌木 Shrub & 竹子 Bamboo & 34 \\
& 其他 Others & 735 \\
& 小计 Subtotal & 769 \\
藤本 Vine & 草质 Herb & 99 \\
& 木质 Woody & 132 \\
& 其他 Others & 28 \\
& 小计 Subtotal & 259 \\
木本 Tree & 常绿 Evergreen & 509 \\
& 落叶 Deciduous & 181 \\
& 半落叶 Semi-deciduous & 11 \\
& 小计 Subtotal & 701 \\
总计 Total & & 3,363 \\
\hline
\end{tabular}


表7 各植被类型受威胁被子植物的种数及其占 3,363 种受 威胁种的百分比

Table 7 Number of threatened species in some vegetation types and the ratio to 3,363 threatened angiosperms species in China.

\begin{tabular}{lll}
\hline $\begin{array}{l}\text { 植被类型 } \\
\text { Vegetation type }\end{array}$ & $\begin{array}{l}\text { 受威胁物种数 } \\
\text { No. of threat- } \\
\text { ened species }\end{array}$ & $\begin{array}{l}\text { 比例 } \\
\%\end{array}$ \\
\hline 森林 Forest & 2,684 & 84.7 \\
灌丛 Shrub & 854 & 27 \\
荒漠 Desert & 52 & 1.6 \\
草原、草甸等 & 395 & 12.5 \\
Grassland \& meadow & & \\
高山植被 Alpine vegetation & 48 & 1.5 \\
湿地(沼泽与水生植被) & 42 & 1.3 \\
Wetlands (bogs and aquatic) & & \\
人工植被 Artificial vegetation & 422 & 13.3 \\
其他生境类型 Other habitats & 283 & 8.9 \\
\hline
\end{tabular}

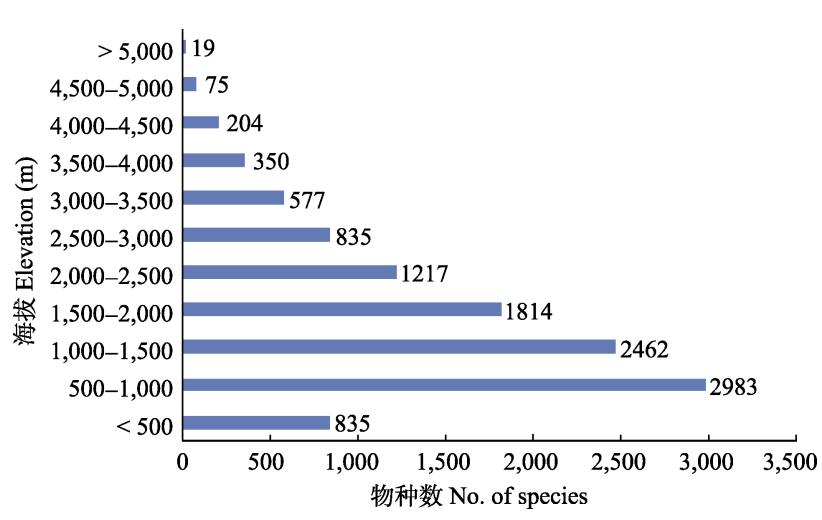

图3 被子植物受威胁种的海拔分布(部分种类跨几个海拔 段分布)

Fig. 3 Elevation status of threatened species of China's angiosperms. Some species cover several sections.

主要分布在 $500-1,000 \mathrm{~m} 、 1,000-1,500 \mathrm{~m} 、 1,500-$ $2,000 \mathrm{~m}$ 这 3 个海拔段, 各有2,983种、2,462种和 1,814 种(图3)。究其原因, 我们认为 $2,000 \mathrm{~m}$ 以下的中低海 拔地区是植物类群密集分布区，同时也是农耕活动 和城镇用地等人类活动最为频繁的地区, 生境丧失 及破碎化最为严重, 野生物种生存压力也最大。

\section{5 致危因子}

IUCN将导致物种濒危的因子归结为生境退化 或丧失、人为过度利用、物种内在原因、外来入侵 种和其他种间竞争、环境污染、自然灾害和极端气 候变化等几种类型(http://www.iucnredlist.org)。这些 因子将带来物种居群衰退、分布范围缩小或个体数 量下降等不利影响, 从而导致物种受威胁、濒危甚 至灭绝。本文按照IUCN致危因子分类方案, 分析部 分中国被子植物受威胁种的致危因子(表8)。结果显 示, 生境丧失和退化是中国被子植物致危的最大因
表8 中国被子植物的威胁因子

Table 8 Factors influencing the threatened (CR, EN, and VU) angiosperms taxa in China

\begin{tabular}{lll}
\hline $\begin{array}{l}\text { 威胁因子 } \\
\text { Threats }\end{array}$ & $\begin{array}{l}\text { 影响物种数 } \\
\text { Threatened } \\
\text { species number }\end{array}$ & $\begin{array}{l}\text { 比例 } \\
\%\end{array}$ \\
\hline $\begin{array}{l}\text { 生境退化或丧失 } \\
\text { Habitat degradation or loss }\end{array}$ & 2,116 & 84.1 \\
$\begin{array}{l}\text { 直接采挖或砍伐 } \\
\text { Logging or harvesting }\end{array}$ & 963 & 38.3 \\
$\begin{array}{l}\text { 环境污染 Environmental pollution } \\
\text { 自然灾害和气候变化 }\end{array}$ & 17 & 0.7 \\
$\begin{array}{l}\text { Natural disasters and climate change } \\
\text { 物种内在因子 Internal factors }\end{array}$ & 39 & 1.6 \\
种间影响 Interspecific effects & 33 & 14.2 \\
\hline
\end{tabular}

子，涉及2,116种，占分析种数的 $84.1 \%$ 。农业生产活 动，包括开荒造林、放牧、路网建设及城镇化等均 是导致植物生境丧失和破碎化的驱动力。人为过度 采集和利用野生植物资源是我国被子植物致危的 第二位因子，涉及 963 个物种，占所分析对象的 $38.3 \%$ 。物种内在因子致危的占第三位，涉及357种， 约占 $14.2 \%$, 主要表现在种群数量过少, 扩散繁殖 能力弱, 或自交不育等。近年来, 物种生物学研究 越来越多地揭示物种的濒危内因, 例如, 国内学者 对于丁香(Syringa spp.) (付志军, 1998)、苏铁(Cycas spp.) (吴萍和张开平, 2008)、牡丹(Paeonia spp.) (周 仁超等, 2002)、明党参(Changium smyrnioides) (邱英 雄和傅承新, 2001)、裂叶沙参(Adenophora lobophylla) (张文辉等, 2002)、夏腊梅(Calycanthus chinensis) (周世良和叶文国, 2002)和望天树(Parashorea chinensis) (间兴富和曹敏, 2008)等的研究工作, 揭 示了这些物种的内在濒危机制。此外，包括外来入 侵种在内的种间竞争、自然灾害、环境污染和全球 变化等诸多因素也给物种生存带来负面影响, 直至 导致物种的灭绝(魏辅文等, 2014)。我们的调查结果 也显示, 我国有关入侵种的研究在逐年增多, 而环 境污染和全球气候变化对植物种群影响的研究仍 然很少见(表8), 今后应当加强。

在分析被子植物濒危状况时发现，同一物种往 往遭受多种致危因子的作用, 其中某种因子起着主 要作用。另外, 致危因子也随时间或不同种群而变 化, 一旦威胁因子发生变化, 物种所受的影响包括 威胁的程度也可能随之变化。因此, 基于此次中国 高等植物红色名录调查评估结果, 建立针对我国受 
威胁物种或保护关注物种的动态监测, 从而找到并 消除物种濒危因子、促进物种保护将是今后保护生 物多样性的有效途径和一项重要工作。

\section{6 与《中国物种红色名录》(2004)比较}

IUCN建议对同一类群或同一区域的前后不同 批次/版本红色名录进行对比(Bubb et al, 2009), 以 便查明类群灭绝风险的变化趋势, 识别灭绝风险快 速变化的区域或生态系统, 包括分析濒危等级变化 的原因等, 为生物多样性研究和制订保护对策提供 依据。如前文所述, 2004年的《中国物种红色名录, 第一卷, 红色名录》(汪松和解炎, 2004) 是我国第一 个采用IUCN红色名录标准3.1版本进行评估的工作, 它虽然只选择评估了中国部分物种, 但所涉及的 4,182种被子植物均涵盖在本文的评估范围内, 而 且所评受威胁种数量 $(3,624$ 种)与本文(3,363种)比较 接近。因此, 我们认为, 将本文评估结果与 2004 年 名录的对比, 有一定的参考价值。

对比结果表明, 2004年名录中约10\%的物种(名 称)根据最新分类学研究结果已被归并、降级或标识 为错误鉴定, 其余物种中 $1 / 3$ 本次评为非受威胁等 级。进一步的分析表明, 两个名录的共同物种中, 约 $40 \%$ 的物种等级保持不变, 约 $10 \%$ 的物种被本次 评估列为数据缺乏(DD) 级, 另外 $10 \%$ 的物种被提升 濒危等级, 甚至灭绝等级。例如, 南川盆距兰 (Gastrochilus nanchuanensis)由2004年的CR变成EX, 尖 花藤(Friesodielsia hainanensis)从VU等级也变成EX, 等等。这些对比结果除了说明过去十余年间, 中国 植物分类学和保护生物学研究结果对濒危物种评 估产生了影响外, 也说明了一些物种的濒危状况得 到缓解, 另一些则保持稳定或变得更为严峻。当然, 这只是一个初浅的对比分析, 更详细的分析结果, 包括产生这些变化的背景原因有待于深入研究和追 踪报道。

\section{4 小结}

动植物濒危等级被广泛应用于衡量生物多样 性与生态系统健康与否, IUCN濒危物种红色名录 的宗旨是为显示物种灭绝的相对风险, 可用于建立 生物多样性保护优先顺序(Bilz et al, 2011; 藏春金金 等, 2016)。中国首次完成了全部野生被子植物的灭 绝风险评估。评估结果显示: (1)在所评估的30,068 种中国被子植物中, 40 种灭绝(含 $\mathrm{EX} 、 \mathrm{EW} 、 \mathrm{RE}$ ),
3,363种受威胁(含CR、EN、VU), 2,538种近危(NT), 21,132 种无危(LC), 2,995种缺乏数据(DD)。在含 20 种以上的科中, 受威胁程度最高的是木兰科, 受威 胁种占 $67.3 \%$; 其次是猕猴桃科，占63.2\%; 随后是 薯蓣科、金缕梅科和马自铃科等。(2)受威胁物种的 空间分布也不均衡, 主要集中在横断山区、华中、 台湾、秦岭及周边地区，与我国物种多样性的分布 格局总体相似; 从海拔高度上看, 则集中分布在 500-2,000 m的中低海拔地段; (3)受威胁物种主要 分布在各类森林生境中, 占 $84.7 \%$, 其次是灌从, 人 工植被和草原草甸分列三、四位; (4)导致中国被子 植物濒危的首要因子是人类生产活动导致的原生 森林消失和生境退化, 过度采集和植物自身缺陷位 列第二、三因子, 此外, 种间竞争、环境污染、自 然灾害和极端气候变化也是中国被子植物濒危的 重要致危因子。

通过与2004年红色名录的初步对比, 我们不仅 发现了中国被子植物濒危状况的一些变化趋势, 也 进一步认识了 IUCN关于红色名录是动态而非终点 的思想。只有对红色名录进行适时更新, 根据土地 利用情况(对生境的影响)、物种保护措施和分类学 修订进展进行评估信息及濒危等级的更新, 才能真 实反映物种的濒危状态和灭绝风险, 为生物多样性 监测、保护及国际履约提供科学可靠依据。

致谢: 中国高等植物红色名录评估是一项历时多年 的系统工程，凝结着许多人的智慧和力量。感谢环 境保护部对项目的支持。感谢中国科学院植物所提 供工作条件; 感谢众多植物学专家提供物种评估 信息并审查评估结果; 感谢所有对本文做出贡献 的老师、同事和同学。

\section{参考文献}

Bilz M, Kell SP, Maxted N, Lansdown RV (2011) European Red List of Vascular Plants. Publications Office of the European Union, Luxembourg.

Bubb PJ, Butchart SHM, Collen B, Dublin H, Kapos V, Pollock C, Stuart SN, Vié JC (2009) IUCN Red List IndexGuidance for National and Regional Use. IUCN, Gland, Switzerland.

Convention on Biological Diversity (2012) Global Strategy for Plant Conservation: 2011-2020. Botanic Gardens Conservation International, Richmond, UK.

de Grammont PC, Cuarón AD (2006) An evaluation of 
threatened species categorization systems used on the American continent. Conservation Biology, 20, 14-27.

Fu LK, Jin JM (1991) The Red Data Book of China's Plants, Vol. 1: Rare and Endangered Species (English Edition). Science Press, Beijing.

Fu ZJ (1998) The conservation and utilization of rare and endangered plants in Qinling range. Mountain Research, 16, 325-329. (in Chinese with English abstract) [付志军 (1998) 秦岭珍稀濒危植物资源的利用价值与保护. 山地研究, 16, 325-329.]

Hilton-Taylor C (2000) The IUCN/SSC Red List Program: Toward the 2000 IUCN Red List of Threatened Species. Species, 33, 21-29.

Hu QM, Xia NH, Wu DL (2003) Rare and Precious Plants of Hong Kong. Agriculture, Fisheries and Conservation Department, Hong Kong. (in Chinese) [胡启明, 夏念和, 吴德 邻 (2003) 香港稀有及珍贵植物. 香港渔农自然护理署.]

IUCN (2001) IUCN Red List Categories and Criteria, Version 3.1. IUCN Species Survival Commission, Gland, Switzerland.

IUCN (2012a) IUCN Red List Categories and Criteria, Version 3.1. 2nd edn. IUCN, Gland, Switzerland and Cambridge, UK.

IUCN (2012b) Guidelines for Application of IUCN Red List Criteria at Regional and National Levels, Version 4.0. Gland, Switzerland and Cambridge, UK

IUCN (2012c) Rules of Procedure IUCN Red List Assessment Process 2013-2016. Version 2.0. Approved by the IUCN SSC Steering Committee in September 2012. http://www. iucnredlist.org/documents/Rules_of_Procedure_for_Red_List_ 2013-2016.pdf

IUCN Standards and Petitions Subcommittee (2011) Guidelines for using the IUCN Red List Categories and Criteria. Version 9.0. Prepared by IUCN Standards and Petitions Subcommittee. http://www.iucnredlist.org/documents/RedListGuidelines.pdf. (accessed on 2011-08-30)

Miller RM, Rodríguez JP, Aniskowicz-Fowler T, Bambaradeniya C, Boles R, Eaton MA, Gärdenfors U, Keller V, Molur S, Walker S, Pollock C (2007) National threatened species listing based on IUCN criteria and regional guidelines: current status and future perspectives. Conservation Biology, 21, 684-696.

Mittermeier RA, Myers N, Thomsen JB, da Fonseca GAB, Olivieri S (1998) Biodiversity hotspots and major tropical wilderness areas: approaches to setting conservation priorities. Conservation Biology, 12, 516-520.

Myers N, Mittermeier RA, Mittermeier CG, da Fonseca GAB, Kent J (2000) Biodiversity hotspots for conservation priorities. Nature, 403, 853-858.

Novacek MJ, Cleland EE (2001) The current biodiversity extinction event: scenarios for mitigation and recovery. Proceedings of the National Academy of Sciences, USA, 98, 5466-5470.
Qin WH, Jiang MK, Xu WG, He ZH (2012) Assessment of in situ conservation of 1,334 native orchids in China. Biodiversity Science, 20, 177-183. (in Chinese with English abstract) [秦卫华, 蒋明康, 徐网谷, 贺昭和 (2012) 中国 1,334种兰科植物就地保护状况评价. 生物多样性, 20, 177-183.]

Qiu YX, Fu CX (2001) Studies on the endangerment mechanism of and conservation strategies for Changium smyrnioides. Biodiversity Science, 9, 151-156. (in Chinese with English abstract) [邱英雄, 傅承新 (2001) 明党参的濒危 机制及其保护对策研究. 生物多样性, 9, 151-156.]

Raimondo D, von Staden L, Donaldson JS (2013) Lessons from the conservation assessment of the South African megaflora. Annals of the Missouri Botanical Garden, 99, 221-230.

Raimondo D, von Staden L, Foden W, Victor JE, Helme NA, Truner RC, Kamundi DA, Manyama PA (2009) Red List of South African Plants. South African National Biodiversity Institute, Pretoria.

Rohan JCC, Stephen MD, Elisabeth S (2009) An approach for regional threat assessment under IUCN Red List criteria that is robust to uncertainty: The Fiordland bottlenose dolphins are critically endangered. Biological Conservation, 142, 1570-1579.

Royal Botanic Gardens Kew (2016) The State of the World's Plants Report 2016. Royal Botanic Gardens, Kew.

State Forestry Administration of The People's Republic of China, Ministry of Agriculture of The People's Republic of China (in Chinese) (1999) State's Key Protected List of Wild Plants [国家林业局和国家农业部 (1999) 国家重点 保护野生植物名录(第一批), 1999年8月4日颁布, 1999年9 月9日起施行.]

The Biodiversity Committee of Chinese Academy of Sciences (2016) Catalogue of Life China. Science Press, Beijing. [中 国科学院生物多样性委员会(编) (2016) 中国生物物种名 录. 科学出版社, 北京.]

The Biodiversity Committee of Chinese Academy of Sciences (ed.) (2016) Catalogue of Life China 2017 Annual Checklist. CD-ROM. Science Press, Beijing. [中国科学院生物多 样性委员会 (编) (2016) 中国生物物种名录2017版, CD-ROM. 科学出版社, 北京.]

The Endangered Species Import \& Export Management Office Of the People's Republic Of China, Endangered Species Scientific Commission, People's Republic of China (2013) Appendix I, II and III of Convention on International Trade of Endangered Species of Wild Fauna and Flora, Adopted at Cop 16 of CITES. (in Chinese) [中华人民共和国濒危物种 进出口管理办公室, 中华人民共和国濒危物种科学委员 会 (2013) 濒危野生动植物国际贸易公约附录I、附录 II 和附录 III.] http: //www.cites.org.cn/(accessed on 201705-12)

Wang JC, Chiou WL, Chang HM (eds) (2012) A Preliminary Red List of Taiwanese Vascular Plants. Endemic Species Research Institute \& Taiwan Society of Plant Systematics. 
Nantou, Taiwan. (in Chinese with English abstract) [王振哲, 邱文良, 张和明 (主编) (2012) 台湾维管植物红皮书初评 名录. 特有生物研究保育中心及台湾植物分类学会, 南 投, 台湾.]

Wang LS, Jia Y, Zhang XC, Qin HN (2015) Overview of higher plant diversity in China. Biodiversity Science, 23, 217-224. (in Chinese with English abstract) [王利松, 贾渝, 张宪春, 覃海宁 (2015) 中国高等植物多样性. 生物多样 性, 23, 217-224.]

Wang S, Xie Y (2004) China Species Red List, Vol. 1: Red List. Higher Education Press, Beijing. (in Chinese with English abstract) [汪松, 解炎 (2004) 中国物种红色名录, 第1 卷: 红色名录. 高等教育出版社, 北京.]

Wei FW, Nie YG, Miao HX, Lu H, Hu YB (2014) Advancements of the researches on biodiversity loss mechanisms (in Chinese). China Science Bulletin (Chinese Version), 59, 430-437. (in Chinese with English abstract) [魏辅文, 聂永 刚, 苗海霞, 路浩, 胡义波 (2014) 生物多样性丧失机制 研究进展. 科学通报, 59, 430-437.]

Wu CY, Raven PH, Hong DY (eds.) (2013) Flora of China, Introduction, Vol.1. Sciences Press and Missouri Botanic Garden Press,, Beijing and St. Louis.

Wu P, Zhang KP (2008) Status of Cycas spp. plants in Yunnan and measures for their protection. Forest Inventory and Planning, 33(4), 116-119. (in Chinese with English abstract) [ 吴萍, 张开平 (2008) 云南苏铁植物的现状及保护对策. 林业调查规划, 33(4), 116-119.]

Yan XF, Cao M (2008) The endangered causes and protective strategies for Shorea wantianshuea, a tropical rain forest tree species in Xishuangbanna. Journal of Fujian Forestry Science and Technology, 35, 187-191. (in Chinese with English abstract) [间兴富, 曹敏 (2008) 热带雨林濒危树 种望天树的致危原因及保护策略. 福建林业科技, 35, 187-191.]

Zamin TJ, Baillie JEM, Miller RM, Rodríguez JP, Ardid ANA, Collen BEN (2010) National Red Listing beyond the 2010 target. Conservation Biology, 24, 1012-1020.

Zang CX, Cai L, Li JQ, Wu XP, Li XG, Li JS (2016) Preparation of the China Biodiversity Red List and its significance for biodiversity conservation within China. Biodiversity Science, 24, 610-614. (in Chinese with English abstract) [菣 春金金, 蔡蕾, 李佳琦, 吴晓莆, 李晓光, 李俊生 (2016) 《中国生物多样性红色名录》的制订及其对生物多样性 保护的意义. 生物多样性, 24, 610-614.]

Zhang WH, Zu YG, Liu GB (2002) Population ecological characteristics and analysis on endangered cause of ten endangered plant species. Acta Ecologica Sinica, 22, 15121520. (in Chinese with English abstract) [张文辉, 祖元刚, 刘国森 (2002) 十种濒危植物的种群生态学特征及致危 因素分析. 生态学报, 22, 1512-1520.]

Zhang YW, Yang HP, Chen B, Yang XM, Shen ZH (2009) Research progress of Orchidaceae in China. Guizhou Science, 27(4), 78-85. (in Chinese with English abstract) [(张 玉武, 杨红萍, 陈波, 杨晓梅, 沈峥华 (2009) 中国兰科 植物研究进展概述. 贵州科学, 27(4), 78-85.]

Zhao LN, Li JY, Liu HY, Qin HN (2016) Distribution, congruence, and hotspots of higher plants in China. Scientific Reports, 6, 19080.

Zhou RC, Yu DM, Huang YQ, Yang RG (2002) Endangered mechanism and conservative strategies of Paeonia rockii. Territory \& Natural Resources Study, 3, 74-75.(in Chinese with English abstract) [周仁超, 于东明, 黄言强, 杨仍阁 (2002) 紫斑牡丹的濒危机制与保护对策. 国土与自然资 源研究, 3, 74-75.]

Zhou SL, Ye WG (2002) The genetic diversity and conservation of Sinocalycanthus chinensis. Biodiversity Science, 10, 1-6. (in Chinese with English abstract) [周世良, 叶文国 (2002) 夏腊梅的遗传多样性及其保护. 生物多样性, 10, $1-6$.

(责任编委: 唐志尧 责任编辑: 时意专)

\section{附录 Supplementary Material}

附录1 IUCN物种红色名录等级及标准(摘要)

Appendix 1 Summary of IUCN Red List categories and criteria

http://www.biodiversity-science.net/fileup/PDF/2017156-1.pdf 
覃海宁等. 中国被子植物濒危等级的评估. 生物多样性, 2015, 25 (7): 745-757.

http://www.biodiversity-science.net/CN/10.17520/biods.2017156

\section{附录1 IUCN濒危物种红色名录等级定义及量化指标(摘自IUCN, 2012a, b)}

Appendix 1 Categories and Criteria of China Higher Plant Red List

\section{红色名录等级 THE CATEGORIES (Figure 1)}

\section{一、灭绝 (Extinct, EX)}

当一分类群无疑其最后个体已死亡时, 即列为灭绝级。若在其所有历史分布范围内, 已知或可能之生育地, 适当之时间(考虑昼夜、季节及年度变化), 进行彻底之调查后, 没有 发现任何个体, 则应推定为灭绝。

\section{二、野外灭绝(Extinct in the Wi1d, EW)}

一分类群只在栽培、饲养状况下生存或只剩下远离原分布地以外之移植驯化种群时, 这个分 类群即列为野外灭绝。若在其所有历史分布范围内, 已知或可能之生育地, 适当之时间(考 虑昼夜、季节及年度变化), 兼顾此一分类群之生活史及生活型 (Life cycle and Life form) 之 情况下，进行彻底之调查后，没有发现其个体，则应推定为野外灭绝。

* 地区灭绝(Regional Extinct, RE) *IUCN (2003)

当一分类群在一个地区具有生殖能力的最后个体无疑已在该地区野外死亡或消失时, 或一访 问类群(visitor，指一分类群不在该地生殖，但现在或近一世纪某些时期规律性出现，如候鸟) 的最后个体已在该地区野外死亡或消失时, 即列为地区灭绝级。

\section{三、极危 (Critically Endangered, CR)}

当一分类群符合后列极危等级 $\mathrm{A}$ 至 $\mathrm{E}$ 之标准中之任一项时, 应列为极危, 它被认为在野外 面临极高之灭绝风险。

\section{四、濒危 (Endangered, EN)}

当一分类群符合后列濒危等级 $\mathrm{A}$ 至 $\mathrm{E}$ 之标准中之任一项时, 应列为濒危, 它被认为在野外 面临非常高之灭绝风险。

\section{五、易危 (Vulnerable, VU)}

当一分类群符合后列易危等级 $\mathrm{A}$ 至 $\mathrm{E}$ 之标准中之任一项时, 应列为易危, 它被认为在野外 面临高之灭绝风险。 


\section{六、近危 (Near Threatened, NT)}

一分类群根据基准评估后, 在目前尚未达极危、濒危或易危之标准, 但非常接近或在近期内 有可能符合标准者。

\section{七、无危(Least Concern, LC)}

一分类群根据基准评估后，未达极危、濒危、易危或近危之标准。广泛分布及数量多的分类 群属于此类。

\section{八、数据缺乏 (Data Deficient, DD)}

由于缺乏足够资料致无法根据其分布或种群状况，来直接(或间接)评估其灭绝风险的分类 群。归于此级的分类群可能已被充分研究, 其生物学知识也充分了解, 但欠缺数量及/或分 布的正确数据。数据不足级不属于受威胁的等级之一。归于此级的分类群表示需要更多信息, 也有可能在未来的研究将其划分到适当的受威胁等级。重要的是如何善加利用已有的数据, 也要特别注意在「数据不足」及其他保育等级间进行选择的许多个案。若一分类群预期其分 布范围是相对局限或最后之纪录迄今已有相当长的期间, 则将其列入受威胁等级是合理的。

* 不适宜评估（不适用） (Not Applicable, NA) *IUCN (2003)

在地区等级被视为没有资格评估的分类群, 可能因在该地区不是野生种群或不是其自然生育 范围, 或只是流浪者(vagrant, 在一地区只是偶然出现的分类群)。

\section{九、未评估 (Not Evaluated, NE)}

未根据基准进行评估的分类群。 


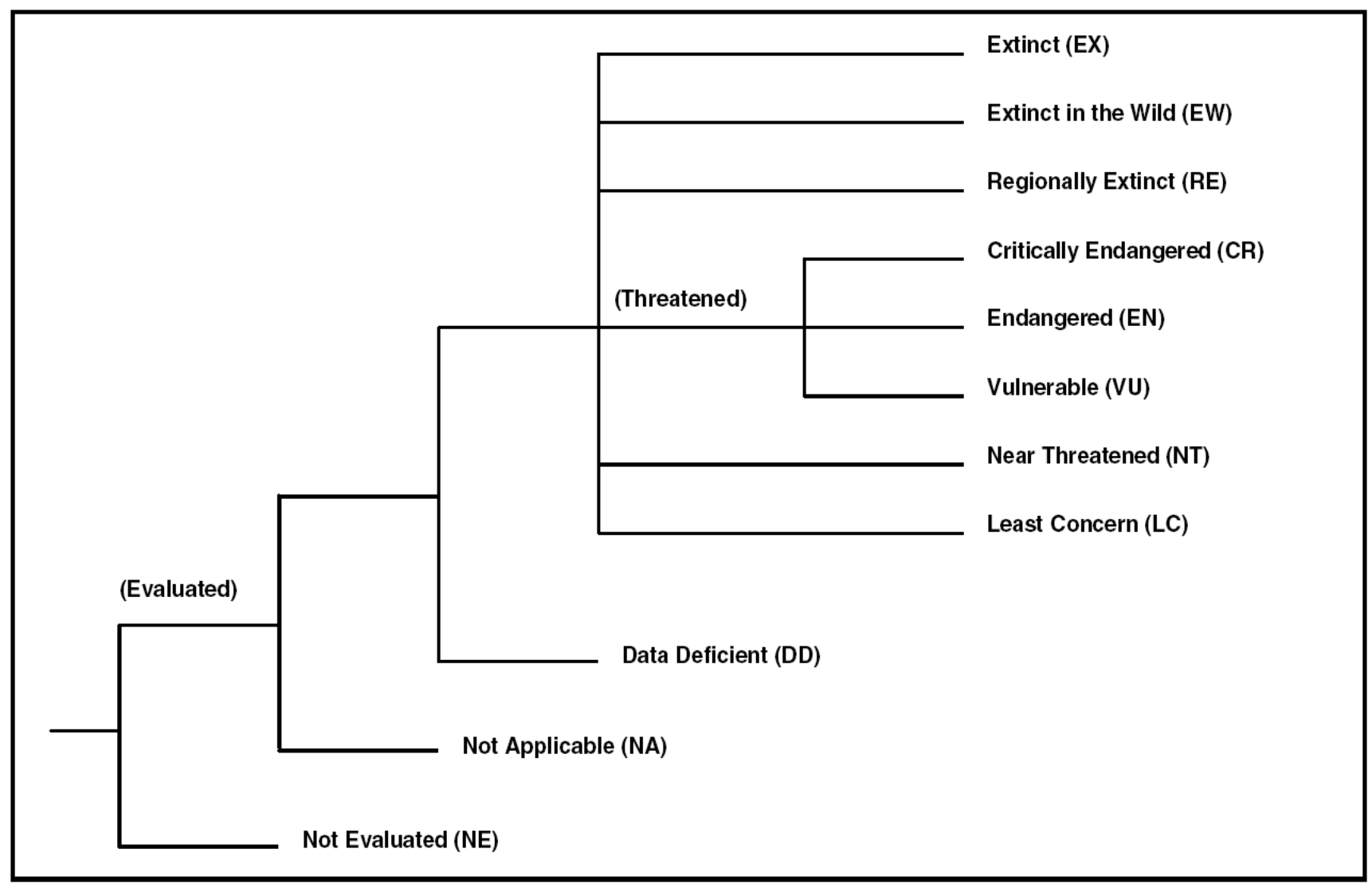

Figure 1. Structure of the categories at regional level. 
表 1 极危、易危及易危等级之评估指标简表

\begin{tabular}{|c|c|c|c|c|c|}
\hline & $\mathrm{A}$ 种群 ${ }^{1}$ 减少 & $\begin{array}{l}\mathrm{B} \text { 分布区小, 衰退或 } \\
\text { 波动 }\end{array}$ & $\begin{array}{l}\mathrm{C} \text { 种群小并在衰 } \\
\text { 退 }\end{array}$ & $\begin{array}{l}\mathrm{D} \text { 小或局限 } \\
\text { 分布的种群 }\end{array}$ & $\begin{array}{l}\mathrm{E} \text { 定量分 } \\
\text { 析 }\end{array}$ \\
\hline & $\begin{aligned} & \text { A1: } \text { 过去 } 10 \text { 年 } \\
& \text { 或三世代 } \\
& \text { 内种群降 } \\
& \text { 低的比例, } \\
& \text { 其降低的 } \\
& \text { 原因是可 } \\
& \text { 逆转且被 } \\
& \text { 了解且停 } \\
& \text { 止的 } \\
& \text { A2-4: 估计过去 } \\
& \text { 或未来(或 } \\
& \text { 二者) } 10 \text { 年 } \\
& \text { 或三世代 } \\
& \text { 内种群降 } \\
& \text { 低的比例 }\end{aligned}$ & $\begin{array}{l}\text { B1: 分布区域 }{ }^{3} \text { 且 } \\
\text { 符合 a-c 任两条: } \\
\text { a. 严重分割或只 } \\
\text { 有 } 1, \leq 5, \leq 10 \text { 个地点 } \\
\text { b. 持续衰退 c. 极 } \\
\text { 度波动 } \\
\text { B2: 实际占有面积 }{ }^{4} \text {, } \\
\text { 并符合 a-c 任两条: } \\
\text { a. 严重分割或只 } \\
\text { 有 } 1, \leq 5, \leq 10 \text { 个地点 } \\
\text { b. 持续衰退 c. 极 } \\
\text { 度波动 }\end{array}$ & $\begin{array}{l}\text { 成熟个体 }{ }^{5} \text { 数少 } \\
\text { 于下列数目, 且 } \\
\text { 有下列情形之一 } \\
\text { 持续下降: }\end{array}$ & $\begin{array}{l}\text { D1 种群成 } \\
\text { 熟个体数 } \\
\text { D2 易受人 } \\
\text { 类 活 动影 } \\
\text { 响, 可能在 } \\
\text { 极短时间成 } \\
\text { 为严重濒临 } \\
\text { 绝灭, 甚至 } \\
\text { 绝灭。 }\end{array}$ & $\begin{array}{l}\text { 使用定量 } \\
\text { 模式评估 } \\
\text { 灭绝风险 }\end{array}$ \\
\hline $\begin{array}{l}\text { 极 危 } \\
\mathrm{CR}\end{array}$ & $\begin{array}{l}\text { A1. } \geq 90 \% \\
\text { A2-4: } \geq 80 \%\end{array}$ & $\begin{array}{l}\text { B1. }<100 \mathrm{~km}^{2} \\
\text { B2. }<10 \mathrm{~km}^{2}\end{array}$ & $\begin{array}{l}<250 \\
\text { 1. } 10 \text { 年或三个 } \\
\text { 世代内持续 } \\
\text { 下降至 少 } \\
25 \% \\
\text { 2. (a) 特殊种群 } \\
\text { 结构或(b) 剧烈 } \\
\text { 变动 }\end{array}$ & D1 $<50$ & $\begin{array}{l}\text { 今 后 } 10 \\
\text { 年或三世 } \\
\text { 代内野外 } \\
\text { 绝灭机率 } \\
\geq 50 \% \text { 。 }\end{array}$ \\
\hline $\begin{array}{l}\text { 濒 危 } \\
\mathrm{EN}\end{array}$ & $\begin{array}{l}\text { A1. } \geq 70 \% \\
\text { A2-4: } \geq 50 \%\end{array}$ & $\begin{array}{l}\text { B1. }<5000 \mathrm{~km}^{2} \\
\text { B2. }<500 \mathrm{~km}^{2}\end{array}$ & $\begin{array}{l}<2,500 \\
1.5 \text { 年或 } 2 \text { 个世 } \\
\text { 代内持续下降至 } \\
\text { 少 } 20 \% \\
\text { 2. (a)特殊种群 } \\
\text { 结构或(b) 剧烈 } \\
\text { 变动 }\end{array}$ & $\mathrm{D} 1<250$ & $\begin{array}{l}\text { 今后 } 20 \\
\text { 年或五世 } \\
\text { 代内野外 } \\
\text { 绝灭机率 } \\
\geq 20 \% \text { 。 }\end{array}$ \\
\hline
\end{tabular}




\begin{tabular}{|c|c|c|c|c|c|}
\hline $\begin{array}{l}\text { 易 危 } \\
\text { VU }\end{array}$ & $\begin{array}{l}\mathrm{A} 1 \geq 50 \% \\
\mathrm{~A} 2-4: \geq 30 \%\end{array}$ & $\begin{array}{l}\text { B1 }<20000 \mathrm{~km}^{2} \\
\text { B2 }<2000 \mathrm{~km}^{2}\end{array}$ & $\begin{array}{l}<10,000 \\
1.10 \text { 年或三个 } \\
\text { 世代内持续下降 } \\
\text { 至少 } 10 \% \\
\text { 2. (a) 特殊种群 } \\
\text { 结构或(b) 剧烈 } \\
\text { 变动 }\end{array}$ & $\begin{array}{l}\mathrm{D} 1<1000 \\
\mathrm{D} 2 \text { 种群占 } \\
\text { 有面积 }<20 \\
\mathrm{~km}^{2} \text { 或地点 } \\
<5 \text { 个 }\end{array}$ & $\begin{array}{l}\text { 今后 } 100 \\
\text { 年内野外 } \\
\text { 绝灭机率 } \\
\geq 10 \%\end{array}$ \\
\hline
\end{tabular}

${ }^{1}$ 种群及种群大小 (Population and Population Size): 红色名录中所谓种群有其特殊意义, 不 同于生物学上一般的用法。在此定义为一个分类群的总个体数。

2 世代 (Generation): 世代长度是目前种群中亲本的平均年龄, 世代长度反应种群中能育个 体的转换率。

3 分布区 (Extent of occurrence, EOO): 一个分类群除流浪者(vagrancy)外, 所有已知、推论或 预测位置的最短连续影像边界所包含的区域。分布区域的度量可排除此分类群全部分布范 围内不连续或跳跃的部份(例如明显不适合的栖地)。分布区域通常可用最小凸多边形 (minimum convex polygon)度量。

4 实际占有面积 (Area of occupancy, AOO): 一个分类群除流浪者外在其分布区域内实际占 有的面积。一个分类群在其分布区域内可能包含不适合或未占据的栖地, 故通常不会遍布 其分布区域。实际占有面积的大小为度量尺度的函数, 应考虑与分类群相关的生物学、威 胁的性质以及可用的数据以选择适当的尺度。

5 成熟个体 (Mature individuals): 指已知、估计或推测的具有生殖能力的个体数, 